\title{
Os espaços de recepção transnacional dos filmes: propostas para uma abordagem semiopragmática
}

\author{
Mahomed Bamba*
}

\begin{abstract}
Resumo: Quais são as determinações contextuais e institucionais que intervêm na recepção transnacional dos filmes? Seguindo uma linha de reflexão que se situa entre as abordagens geopolítica e semiopragmática do cinema contemporâneo, tecemos algumas considerações teóricas e metodológicas sobre os modos de leitura e interpretação do world cinema nos espaços acadêmicos. Revisamos as principais concepções teóricas sobre o fenômeno de "transnacionalidade" cinematográfica. Examinamos a lógica de formação de comunidades de interpretação, os sistemas de valores e os horizontes de expectativas no conjunto heteróclito definido por Elsaesser e Hagener (2010) como "comunidade transnacional de ideias". Partimos dessa categoria (geográfica e, ao mesmo tempo, teórica) para repensar os estudos do world cinema como um campo de microespaços de comunicação, de recepção e de leitura fílmica (ODIN, 2011). É nessa reconstrução teórica que reavaliamos, por fim, a problemática dos (in)variantes no processo de negociação dos sentidos dos filmes contemporâneos africanos no "espaço discursivo" universitário.
\end{abstract}

Palavras-chave: Cinema transnacional. Recepção. Cinema africano. Semiopragmática.

Eu faço a hipótese que num determinado momento da história, pode-se construir um amplo espaço de comunicação no interior do qual os atores mobilizam processos de produção de sentidos homólogos. (ODIN, 2011, p. 43)

Muitos cineastas africanos, que manifestam em suas obras uma predileção para a imagem do nômade, parecem eles próprios destinados a viver como migrantes que circulam (falta uma palavra aqui) entre festivais, universidades, para apresentar seus trabalhos. (ANDREW, 2003, p.22)

\section{Introdução}

Paralelamente ao enfraquecimento da noção de "nação" ${ }^{1}$ na formalização teórica das práticas cinematográficas e audiovisuais contemporâneas, postula-se um

\footnotetext{
* Doutor em Cinema pela USP-ECA. Professor Adjunto II da Faculdade de Comunicação e do Programa de Pós-Graduação em Comunicação e Cultura Contemporâneas - Poscom da Universidade Federal da Bahia - FACOM/UFBA.
} 
fenômeno de "cinema transnacional" ou "cinema transgeográfico". As transformações estruturais ocorridas no campo do cinema mundial, provocadas, em parte, pelos efeitos da globalização, acarretaram novas lógicas de produção, mas também fizeram emergir novos espaços e modos de recepção (na margem dos tradicionais circuitos de distribuição/exibição e consumo dos filmes em salas de cinema). Nesses espaços, operam outras formas de mediação e outros tipos de determinações institucionais no processo de apropriação e de leitura dos filmes. Essa reestruturação do campo cinematográfico é perceptível tanto nos países ditos "centrais" quanto nos países emergentes e periféricos.

\section{Do cinema nacional ao cinema transnacional}

Com o passar do tempo, a ideia da transnacionalidade do cinema se tornou um conceito chave e operatório no estudo do cinema mundial contemporâneo. O cinema transnacional, enquanto prática transcultural e transfronteiriça, faz acreditar, de um lado, na obsolescência da ideologia das identidades nacionais fixas; por outro lado, a transnacionalidade no campo cinematográfico refere-se simultaneamente aos efeitos da globalização (dominação do mercado mundial do cinema por Hollywood), às respostas dos cinemas não-hegemônicos e às respostas dos cineastas originários dos países ex-colonizadores ou ex-colonizados. O conceito de "transnacionalismo" permite dar conta dos rumos e das mudanças em curso no cinema mundial contemporâneo. Ele ajuda a entender os sentidos das obras de um número crescente de cineastas que se expressam dentro de gêneros audiovisuais com dimensões mais globais, e além das entidades mais ou menos autônomas das nações (EZRA; ROWDEN, 2006). Numa perspectiva mais econômica, alguns autores atribuem a emergência desse cinema sem fronteiras a uma série de fatores que vão do incremento da permeabilidade das fronteiras nacionais, passando pele fenômeno de aceleração do fluxo do capital global, até o fator tecnológico que permite uma maior circulação dos filmes em suporte vídeo, DVD e das facilidades de acesso às novas tecnologias, tanto para os diretores de cinema quanto para os espectadores (EZRA; ROWDEN, 2006).

O principal efeito do impacto desses fatores é a passagem progressiva do cinema dito nacional para um cinema transnacional. Sendo assim, alguns pesquisadores começaram a estudar as diferentes vertentes do cinema mundial contemporâneo numa perspectiva geográfica e geopolítica, com o objetivo de reproblematizar as velhas dicotomias entre centro e periferia presentes em algumas definições das teorias do cinema do terceiro-mundo (e a teoria do terceiro cinema) (STAM, 2003). As transformações estruturais ocorridas no campo do cinema mundial, provocadas, em parte, pelos efeitos da globalização, são perceptíveis tanto no polo da produção como no da recepção: elas acarretaram novas lógicas de coprodução, mas

\footnotetext{
1 Mesmo assim, muitos autores continuam acreditando na fortuna do conceito de "nação" na reflexão cinematográfica. Afinal de contas, categorizar e classificar as filmografias e os cineastas com base em sua suposta origem "nacional" e geográfica pressupõe o reconhecimento e aceitação de um conjunto de traços idiossincráticos e ideológicos que operam ainda nas políticas culturais e no processo de produção e consumo de muitas cinematografias no mundo. Para uma definição do "cinema nacional", cf. HAYWARD (1993); HIGSON (1992) e o excelente livro de FRODON (1998).
} 
também fizeram emergir novos espaços de recepção na margem dos tradicionais circuitos de distribuição/exibição dos filmes. Esses câmbios são perceptíveis tanto nas realidades dos países ditos "centrais" como nas dos países emergentes e periféricos. Nesses espaços operam outras formas de mediação e outros tipos de determinações institucionais no processo de apropriação e de leitura dos filmes (STAM; SHOHAT, 2005). Por exemplo, os filmes feitos pelos cineastas africanos em trânsito (que vivem experiências diaspóricas e no exílio) vêm ampliando os contornos ou abalando as bases dos chamados cinemas "nacionais". Além disso, populações imigrantes passaram a constituir-se em verdadeiras comunidades de interpretação que se definem por um tipo particular de horizonte de expectativa e de usos. Hamid Naficy (2001) conseguiu dar conta dessa nova realidade e dessas transformações em curso no world cinema com um único conceito: "accented cinema". Quanto ao objetivo do seu livro, Naficy (2001) é direto: "This book is centrally concerned with the films that postcolonial, Third World filmmakers have made in their Western sojourn since the 1960s, but several key Russian, European, Canadian, and American filmmakers in exile are also featured"2 (2001, p. 3).

Diferentemente do cinema dominante que tende a se considerar como universal e "sem sotaque", diz Naficy (2001), os filmes dos cineastas que vivem as experiências do exílio, da imigração e da diáspora reivindicam alguma forma de particularismo. Mas são também obras autorais autobiográficas (em alguns casos) e que se situam "nos interstícios das culturas, das práticas cinematográficas". São filmes simultaneamente locais e globais. É neste sentido que os circuitos de distribuição e de recepção (festivais, mostras e exibição universitária, etc.) são vistos por Naficy como uma das dimensões constitutivas dos processos de recepção transnacional dos filmes "com sotaque":

In general interstitial filmmakers must be satisfied with a limited distribution and exhibition of their films; often they must spend extra effort to obtain even that level of exposure. Spectators for their films are not a given but must be means of specialized film tours, festivals, and distribution companies and by relying on video to enter college libraries, university courses, and academic conferences. The emergence of webcasting is likely to considerably improve the distribution and exhibition of their films. (NAFICY, 2001, p. 52). ${ }^{3}$

É nesses interstícios que se realiza uma parte do modo de recepção acadêmica dos filmes. O conceito de accented cinema de Naficy é mais do que uma simples redefinição do velho cinema periférico com um novo nome. Trata-se de uma categoria analítica que tem um grande valor heurístico e ajuda a descrever minuciosamente uma

\footnotetext{
${ }^{2}$ A preocupação central deste livro relaciona-se aos filmes que os cineastas do Terceiro Mundo Pós-Colonial produziram em sua permanência no ocidente desde os anos 1960, mas também vários russos, europeus, canadenses e americanos que também produziram em exílio. (Tradução nossa).

3 Em geral, os cineastas intersticiais devem ficar satisfeitos com uma distribuição e exibição limitadas dos seus filmes; muitas vezes eles devem fazer um esforço extra para obter até mesmo este nível de exposição. Espectadores para os seus filmes não são um dado, mas devem ser meios de chegar a festivais e distribuidoras, e recorrendo ao vídeo para entrar em bibliotecas universitárias, cursos universitários e conferências acadêmicas. O surgimento de webcasting é susceptível de melhorar consideravelmente a distribuição e exibição de seus filmes. (Tradução nossa).
} 
série de experiências cinematográficas que têm a ver com os modos de produção e os modos de recepção. Daí sua importância para nosso estudo sobre a recepção transnacional dos filmes africanos nas universidades ocidentais, isto é, fora da África.

Mesmo sendo vista como um fenômeno contemporâneo, a questão da recepção transnacional dos filmes tem uma relação longínqua com as primeiras formas de apropriação dos filmes estrangeiros em outras áreas culturais no período do primeiro cinema. Yuri Tsivian (1998), por exemplo, define como "recepção cultural" um conjunto de respostas "refletidas, ativas, criativas, intervencionistas ou mesmo agressivas" de uma parcela dos públicos russos ao primeiro cinema entre os anos 1896 e 1920. Numa perspectiva histórica, explica Tsivian, o estudioso das práticas de recepção cultural não se interessa apenas pelos discursos dos críticos, tampouco procura reescrever a história do "espectador-no-texto" ou do "sujeito espectador implicado":

The task of those take up the study of cultural reception is quite similar to that of the Rorschach psychologist: to summarise and interpret the recuurent association and fixed ideas that each culture reads into the "moving smudges" of early cinema. (TSIVIAN, 1998, p. 3). ${ }^{4}$

É à mesma conclusão que chega Germain Lacasse (2000) ao se debruçar no caso de recepção verbal protagonizada pelo "bonimenteur" ou comentador de vistas animadas nos primeiros anos do espetáculo cinematográfico. 0 conferencista, pelo tipo de "cinema oral" que praticava nos espaços de exibição dos filmes, não era apenas um mediador: ele era também um espectador que agia contra a instituição-cinema. A história da relação do "bonimenteur" (este espectador particular) com a instituição do cinema, diz Lacasse, pode ser descrita com base em três características: a apreensão (no sentido do bloqueio de um navio num porto); a legitimação; a resistência. Ou seja, durante os primeiros anos, o cinema é integrado nas outras práticas sócio-culturais pré-existentes. E quando o espetáculo cinematográfico se consagra e se torna um pouco mais narrativo, passa a exigir uma forma de mediação, no espaço da recepção, entre o texto e o público. Sendo assim, o conferencista de vistas animadas "serve de explicação e de legitimação, ele é frequentemente encorajado pelo discurso jornalístico e crítico que busca impor a presença de conferencistas cultos que têm uma elocução cuidadosa" (LACASSE, 2000, p. 24). Com relação aos filmes estrangeiros, a performance interpretativa do conferencista tinha o valor de um gesto de reapropriação cultural nos contextos de recepção canadenses, africanos, japoneses etc. A análise da história do conferencista e de sua função revela aspectos interessantes da prática de recepção transnacional em vários lugares do mundo naqueles primórdios do cinema.

Nos processos de circulação transnacional dos filmes, no contexto do world cinema contemporâneo, encontram-se algumas dessas lógicas de apropriação, de "aculturação" e de leitura descritas por Yuri Tsivian (1998) e Germain Lacasse (2000).

\footnotetext{
${ }^{4}$ A tarefa dos que se ocupam do estudo de recepção cultural é bastante semelhante àquele do psicólogo Rorschach: resumir e interpretar as associações recorrentes e ideias fixas que cada cultura lê nos "borrões em movimento" do primeiro cinema. (Tradução nossa).
} 
Só que no contexto da globalização (período histórico em que se acentua o fenômeno dos fluxos culturais) assistimos a uma proliferação de espaços dedicados à recepção fílmica. A pulverização dos lugares (acompanhada por uma diversificação dos modos de interação com os filmes) nos leva à questão de sua qualificação como espaços e comunidades habitados por sujeitos ligados, às vezes, por um mesmo sistema de valores e um mesmo horizonte de expectativas, inclusive nos espaços onde se elaboram as teorias do cinema. Ao reavaliarem as bases epistemológicas da história dos paradigmas teórico-metodológicos dos estudos do cinema, Thomas Elsaesser e Malte Hagener (2010) partem do pressuposto de que no lugar de uma "teoria" do cinema, existe uma "comunidade transnacional de ideias". Eles situam sua revisão meta-teórica numa perspectiva geopolítica e propõem uma nova introdução à teoria do cinema para o século XXI. Doravante, o fator geográfico (sobretudo a proveniência nacional e linguística dos pesquisadores e dos teóricos) se torna determinante na produção de conceitos, modelos analíticos e metodológicos (2010, p. 10). Com isso, pode-se postular a coexistência de correntes franco-francófonas, germânicas, anglosaxônicas, etc de pensadores do cinema. Entretanto Elsaesser e Hagener reconhecem as limitações dos critérios geográficos, nacionais e linguísticos na "partilha do sentido" e das teorias sobre o cinema. Tais critérios de classificação "marginalizariam" não só contribuições e posições importantes dos teóricos de outros lugares do mundo (Itália, Espanha, América Latina, etc) bem como desconsiderariam a importante contribuição da tradução e da imigração (dos pesquisadores/teóricos/cineastas-teóricos do cinema) na formação dessa "comunidade transnacional de ideias" teóricas do cinema (p. 10). Sendo assim, esses critérios devem ser completados com o estudo do impacto da "lógica discursiva das instituições, das suas estratégias, atividades e publicações". Nessa dinâmica, as cidades, tanto quanto as publicações, os museus, os festivais, os departamentos universitários, as traduções e as cidades não só funcionam como micro-instituições de produção de pensamentos teóricos bem como determinam, ao seu modo, as lógicas discursivas e interpretativas no campo das teorias dos cinemas:

\begin{abstract}
A teoria do cinema se desenvolveu em simbiose com as revistas tais como os Cahiers du Cinéma e Screen, instituições tais como a Cinemathèque française, o British Film Institute (BFI) e o Museum of Art (MoMA), bem como departamentos universitários e festivais e exposições. Deste ponto de vista, as traduções, apropriações e transferências de paradigmas teóricos do cinema, particularmente desde os anos 1960, tais como as teorias semiológicas, psicanalíticas e fenomenológicas, subordinaram-se à sua localização geográfica, e não por sua dinâmica interna de teoria em si. As cidades desempenham indiscutivelmente, um papel importante na produção teórica (...). (ELSAESSER; HAGENER, 2011, p. 11).
\end{abstract}

A "comunidade transnacional de ideias" é uma categoria geográfica e, ao mesmo tempo, teórica. Nossa intenção é partir, portanto, desse conjunto heteróclito definido por Elsaesser e Hagener para, em seguida, repensar e apreender os estudos do world cinema como um campo de micro-espaços de comunicação, de recepção e de leitura fílmica. 


\section{Para uma nova abordagem semiopragmática da recepção transnacional dos filmes}

As noções de "espaço", de "contexto" e de "situação" de recepção têm uma grande importância em nosso estudo da recepção transnacional dos filmes ${ }^{5}$. A área de estudo da recepção existe enquanto campo só por causa de alguns grandes paradigmas e modelos de formalização da espectatorialidade e do processo de leitura. Um desses paradigmas é a pragmática do cinema, perspectiva teórica dentro da qual os processos receptivos e de leitura são estudados a partir do tipo de interação que se cria entre a comunicação fílmica e os públicos em contextos. Procuramos subsídios na semiopragmática de Roger Odin (2011) que é, sem duvida, o estudioso que melhor explorou o valor heurístico do parâmetro do "contexto" na formalização do paradigma da semiopragmática. Livros após livros, artigos após artigos, Odin afinou o modelo semiopragmático, que ele mesmo define como "comunicativo e pragmático". No seu mais recente livro, Les espaces de communication: introduction à la sémiopragmatique (2011), o teórico francês reafirmou as particularidades metodológicas do modelo semiopragmático no meio dos estudos da recepção e da análise fílmicas. $\mathrm{Na}$ verdade, a semiopragmática, confessa o próprio Odin, busca uma saída do imanentismo da semiologia clássica do cinema para chegar a uma perspectiva que ele denomina "pragmático contextualista" (2011, p.17).

É nessas reformulações sucessivas do paradigma semiopragmático que a noção de "espaço de comunicação" acabou substituindo a de "contexto". Trata-se de um espaço de leitura e de recepção que é teoricamente construído (embora com dados empíricos). É um espaço dentro do qual "um feixe de determinações obriga os actantes (emissor e receptor) a produzir sentido sobre um mesmo eixo de pertinência" (ODIN, 2011, p. 19). Por ser uma ferramenta heurística, explica Odin (2000, p.11), a noção de "espaço de comunicação" serve apenas, num estudo da recepção ou na análise fílmica, a levantar previamente uma série de questões. Em seguida, o estudioso busca apreender as diferenças que podem pontuar a maneira como os públicos/espectadores interagem com os textos fílmicos e audiovisuais (inclusive pictóricos e fotográficos) em diversas situações. Ou seja, são os espaços de produção e de recepção que determinam, em última instância, os processos de leitura/interpretação nas experiências estéticas e na comunicação cinematográfica. Sendo assim, os modos de leitura e de afeto, mesmo sendo pré-programados e solicitados durante o processo de produção fílmica, só poderão ser atualizados ou não nos espaços de recepção se houver uma forma de competência por parte dos espectadores. A "competência" espectatorial é formada por uma série de elementos que vão dos mais naturais aos mais simbólicos (incluindo aí o elemento linguístico). Odin condiciona a boa recepção e leitura do filme à mobilização daquilo que chama de "competência comunicacional compartilhada", isto é, o "reservatório de modos de produção de sentidos e afetos" (2011, p.23). É por isso que na formalização semiopragmática da recepção fílmica, a formação do "espaço discursivo", a competência e os modos de produção de sentidos estão numa estreita correlação.

\footnotetext{
5Laurent Creton e Raphaëlle Moine (2012) preferem insistir na noção de "situação" no estudo do cinema, de seus públicos e de seus usos.
} 


\section{Metodologicamente falando}

Optamos por uma abordagem semiopragmática na medida em que nosso interesse está, primeiramente, na construção teórica dos "espaços de comunicação" em que se configuram os modos de leitura acadêmica dos filmes africanos. O primeiro passo na elaboração do procedimento metodológico consistiu em criar um ponto de junção e de conciliação entre a abordagem semiopragmática e a teoria geopolítica dos cinemas contemporâneos mundiais (que se interessa pelos seus modos de recepção transnacional). Procuramos examinar os sistemas de valores, os horizontes de expectativas e as comunidades de interpretação que se formam no decurso da circulação dos filmes africanos no conjunto heteróclito que Elsaesser e Hagner (2010) chamam de "comunidade transnacional de ideias". Como ocorre nos campos da literatura e das outras artes, uma investigação das recepções estrangeiras dos filmes pode interessar, além da análise dos espaços dos eventos em que ocorre a recepção transcultural, pela análise dos paratextos e metatextos produzidos tanto pela crítica especializada quanto pelos discursos prosaicos provenientes do grande público. Tal pesquisa pode concernir também ao campo discursivo formado pelos modos de leitura analítica e teórica dos filmes no contexto acadêmico. Sendo assim, as produções teóricas sobre os cinemas africanos, os dossiês de revistas e periódicos universitários que Ihes são consagrados, bem como as análises de alguns filmes africanos foram lidos como "textos", mas também como "espaços de comunicação".

Preferimos focar no estudo do material discursivo formado nos campos teóricos (espaço do modelo de recepção teórica e analítica, por excelência). Partimos desse campo discursivo (que é, ao mesmo tempo, físico, empírico e abstrato) para, em seguida, reconstruí-los como um mosaico de pequenos "espaços de comunicação". Por fim, a perspectiva semiopragmática nos permitiu completar e superar os limites de um estudo geográfico e geopolítico dos modos de recepção desses cinemas, forçando-nos a compreender tais processos através da análise das interações entre os filmes e seus espectadores-leitores (reais ou hipotéticos). É nessa reconstrução teórica que reexaminamos a questão dos invariantes e das variações no processo de negociação e de produção de sentido dos filmes contemporâneos africanos, particularmente no "espaço acadêmico" (o foco deste artigo). Quais seriam, então, as determinações contextuais que pesam na recepção dos cinemas africanos, uma vez que são incorporados no universo acadêmico como outros componentes do world cinema?

\section{O lugar dos cinemas africanos no espaço institucional universitário}

Numa perspectiva semiopragmática, consideraremos a instituição universitária como um "espaço de comunicação" em que se encena uma modalidade de recepção diferente das da crítica especializada, dos festivais e das mostras e dos circuitos de salas de cinema comerciais. Os pesquisadores universitários que analisam os filmes e os cinemas mundiais são eles próprios espectadores antes de analistas. Mas deixam de se confundir com os espectadores ordinários na medida em que situam sua atividade 
de recepção num contexto de comunicação que Odin (2011, p.132) define simultaneamente como o "espaço de comunicação da análise" e o "espaço universitário". Na maioria dos casos, trata-se de um espaço em que se realiza uma reflexão epistemológica, temática e metodológica a partir de uma seleção de filmes que ganham o estatuto de corpus. Os pesquisadores-estudiosos dos cinemas mundiais tendem a aplicar grades de leitura que correspondem aos seus propósitos teóricometodológicos. Por outro lado, a construção do espaço universitário em torno dos cinemas africanos é fortemente relacionada também com o tipo de competência suigeneris que opera entre os pesquisadores que se debruçam nessas cinematografias e fazem delas seu objeto de investigação.

Tudo isso faz com que o espaço da análise textual, o da interpretação e o da reflexão teórica funcionem como subespaços discursivos de um mesmo campo: o "espaço institucional universitário", contexto de recepção transnacional, por excelência, dos cinemas africanos (depois dos festivais e das mostras). O estudo desse vasto espaço de recepção passa também pela compreensão do processo de legitimação dos estudos dos cinemas africanos em algumas universidades do mundo. Essa legitimação, muitas vezes, tem aspectos ideológicos, políticos e éticos que são inerentes à maneira como a própria instituição universitária se apropria de determinadas formas artísticas.

Enquanto instituição e campo discursivo, as teorizações e as pesquisas acadêmicas sobre os cinemas africanos estão atravessadas por diversas linhas de forças, com algumas regularidades, mas também com alguns momentos de ruptura. Ao serem incorporados nos currículos escolares dos cursos de letras e de literatura comparada, os estudos históricos e analíticos das obras dos cineastas africanos acabaram se realizando seguindo as lógicas de problematização teórica dos sentidos das cinematografias do "terceiro-mundo" ou, simplesmente, do world cinema. Tais lógicas, como sabemos, são as das teorias pós-estruturalistas do cinema, representadas, notadamente, pelos modelos do criticism reading, dos cultural studies e dos modelos de análise contextualista da recepção muito em voga nos EUA. As pesquisas universitárias americanas sobre o universo proteiforme do cinema negro, além dos seus dois principais componentes (o Black cinema britânico e o blaxploitation movie americano), também acabaram carregando os cinemas africanos no seu leque de objetos de estudo. Com isso, estabeleceu-se uma espécie de relação de continuidade e de complementaridade entre os estudos dos cinemas negro-africanos e as pesquisas sobre o Black cinema (o cinema negro britânico e o blaxploitation movie americano). Enquanto Manthia Diawra (1993) problematiza a espectatorialidade "negra" com base nas experiências de identificação e de resistência entre os públicos afro-americanos e os filmes hollywoodianos, outros pesquisadores americanos, por exemplo, dedicaram-se ao estudo do contexto histórico marcado por uma maior aproximação entre os Black auteurs americanos e as diásporas africanas, latinoamericanas, centro-americanas e caribenhas. Segundo Ntongela Masilela (1993), The Los Angeles School of Black Filmmakers foi o contexto, o cenário e a máxima expressão daquela efervescência política, intelectual, intercultural e transnacional. 
É nos interstícios desses contextos, desses jogos de enunciação plural e nesses espaços de comunicação (e espaços discursivos) que convém indagar e explorar as demais formas de recepção transnacional dos cinemas africanos, sobretudo no decurso de sua circulação entre diversos espaços institucionais de recepção e negociação de sentidos. Nesse sentido, a análise dos dossiês de algumas revistas científicas consagradas aos cinemas africanos parece um exercício instigante. O caráter datado desses dossiês ajuda também a compreender melhor a gênese e a evolução do campo discursivo e ideológico bem como dos modelos de análise aplicados aos filmes africanos no espaço acadêmico. As propostas e as intencionalidades das revistas de cinema também apontam para posturas conflitantes dos atores de comunicação nesse espaço.

\section{Os filmes africanos no espaço de comunicação das revistas científicas de cinema}

As revistas científicas e as análises teóricas (que ocupam um lugar de destaque na recepção acadêmica) funcionam também como verdadeiras instituições dentro do espaço universitário. A vocação heurística, científica e epistemológica completa sua dimensão informativa e comunicativa. Através de suas linhas "editoriais" e temáticas e da organização de dossiês específicos dedicados a filmografias e cinematografias, elas configuram e põem em cena práticas hermenêuticas coletivas. De acordo com a perspectiva semiopragmática, podemos encontrar algumas revistas de cinema como verdadeiras instituições e como um "espaço de comunicação" onde se encena boa parte dos modos de recepção analítica dos filmes africanos no contexto universitário. Como eixo de pertinência, escolhemos apenas as revistas que obedecem aos critérios tradicionais de definição "de revista científica". Por outro lado, privilegiamos a análise das revistas que dedicaram um dossiê exclusivo ao tema "cinema africano". Para completar a construção do espaço de comunicação que são as revistas, consideramos as intencionalidades de seus autores ao organizar um dossiê exclusivamente consagrado aos "cinemas africanos". Por fim, atentamos para o país de origem da instituição universitária da revista em questão.

"Por que estudar o cinema africano? Por que fazê-lo agora? Quem deve explicar as imagens do cinema africano? Quem deve reinterpretar as mídias desse continente mal representado? $\mathrm{O}$ que se pode dizer sobre as metodologias críticas que convêm à análise do cinema africano?" É com essas perguntas que a revista bilíngue quebequense de cinema, IRIS n. 18, abriu a introdução da sua décima oitava edição consagrada aos cinemas africanos contemporâneos. Nesse dossiê, com o título significativo New discourses of African cinema/Nouveaux discours du cinéma africain, os organizadores, bem como os autores dos diferentes artigos, procuravam abrir novas perspectivas de discussão e de compreensão dos cinemas africanos pelas perspectivas da análise teórica. Como explica Roger Odin, um texto analítico nos coloca no âmbito do "meta" (isto é, o campo do metatexto, do metadiscursivo) (2011, p.139). O dossiê New discourses se atribui como tarefa criar um espaço de reflexão que é ao mesmo tempo coletiva e epistemológica. De um lado, há uma preocupação 
clara em estudar os filmes africanos na sua individualidade, entendê-los nos seus diversos aspectos e sentidos. Mas, por outro lado, o dossiê tenciona abordar todo o "cinema africano" (pelo menos o daquele período) através de questões de ordem temática, estética, política e, principalmente, de ordem epistemológica (quais metodologias "convêm à análise do cinema africano"?). Para Frank Ukadike, organizador do dossiê, a proposta era reunir os olhares e as leituras cruzados de estudiosos africanos e "ocidentais" numa mesma coletânea, dando assim visibilidade a velhos modos de pensamentos e de leitura/interpretação e negociação dos sentidos dos filmes africanos, dentro de uma perspectiva multidisciplinar.

Para entender todas as lógicas das leituras plurais em revistas acadêmicas ${ }^{6}$ (como as de IRIS, etc), é preciso recontextualizá-las e situá-las na perspectiva da própria evolução dos cinemas africanos (a partir dos anos 1980 e no interior da geografia e da história dos cinemas mundiais contemporâneos). Os principais periódicos de cinema começaram a dedicar dossiês inteiros aos cinemas africanos a partir dos anos 1990, isto é, quase no mesmo período em que alguns cineastas africanos como Cissé, Ouedraogo entre outros despontavam e angariavam reconhecimento e prêmios da crítica especializada pelos tipos de cinema de autor que vinham propondo. Um ano depois de o filme Yeelen (1987) ter conquistado Cannes, era a vez de Yaaba (1989) ser selecionado na Quinzaine des Réalisateurs em Cannes, em 1989. O cineasta de Mali, Souleymane Cissé, e o cineasta do Burkina Faso, Idrissa Ouedraogo, passaram a ser os mais consagrados diretores dos cinemas feitos na África negra e ocidental. Sendo assim, suas obras, como as de outros cineastas que enveredaram pelos rumos do cinema de autor, tornaram-se as mais dignas de ser estudados na academia. É nesses filmes autorais africanos que a comunidade de intérpretes e analistas universitários se debruçou prioritariamente, pois havia a convicção generalizada de que só nesses filmes exigentes havia a essência da novidade estética representada pelos cinemas africanos. No conjunto do dossiê, destacam-se dois artigos: um é de Michel Serceau (teórico francês) e o outro de Dudley Andrew (renomado estudioso e teórico dos cinemas).

Ambos os textos ilustram e resumem bem, a nosso ver, o tipo de horizonte de expectativa e o processo de produção de sentido que predominavam na época (e predominam ainda hoje) na leitura dos cinemas africanos no espaço acadêmico. Na sua leitura narratológica dos cinemas africanos, Serceau (1995) observa que, ao nascer de forma tardia no meio do cinema mundial e num continente sem tradição cinematográfica pré-estabelecida, a aventura do cinema da África ocidental começa com um dilema que se completa com um paradoxo no plano da recepção. Os cineastas africanos, explica Serceau, vão "tomar emprestada sua concepção da narrativa e da representação no cinema ocidental" (1995, p. 39). Mas há um hiato entre o modelo narrativo dominante e ocidental operando nos filmes autorais africanos e o horizonte de expectativa dos públicos africanos. Ao fazerem um cinema pedagógico baseado numa "missão de observação e de análise crítica" da sociedade, os cineastas africanos acabam se distanciando do gosto dos espectadores locais. Ao sobreporem a função

\footnotetext{
${ }^{6}$ No ano 2000, a revista canadense/quebequense CiNéMAs também consagrou o volume 11 de seu número 1 ao tema da escrita e da mise-en-scène nos cinemas da África: "Écritures dans les cinémas d'Afrique". Revista coorganizada por De B'béri Boulu Ebaanda e André Gaudreault.
} 
educadora e desmistificadora do cinema africano acima da sua função de espetáculo e, por outro lado, ao abdicarem do cinema do "real", os cineastas africanos inauguram uma forma de modernidade cinematográfica que só interessa aos públicos de festivais e que os estudiosos do cinema tendem mais a prezar. Mesmo existindo um cinema popular e de gêneros na África, apenas os filmes ditos "de autor" interessam ao espaço acadêmico, pois essas obras autorais correspondem, de certa forma, às categorias teóricas já elaboradas no campo e confirmam as expectativas que alguns críticos e estudiosos franceses e norte-americanos (americanos e canadenses) depositam nas propostas estético-narrativas dos Jeunes cinémas ou dos Cinémas du Sud, como se diz hoje (FRODON, 2004).

\section{Os modos de leitura dos cinemas africanos no espaço discursivo das teorias do World cinema}

Cria-se, portanto, uma espécie de homologia entre os horizontes de expectativa dos filmes africanos e dos seus espectadores-analistas-teóricos (comunidade de espectadores-modelo). No espaço da análise fílmica (onde opera o modo de leitura analítica segundo a perspectiva semiopragmática), os traços de modernidade desses cinemas do sul ou do "terceiro-mundo" são rastreados, descortiçados, comentados e glosados de um texto a outro, de um livro a outro. A suposta "função desmistificadora" reconhecida aos filmes africanos fez com que a leitura "anticolonialista" e "póscolonial" se impusesse como o principal e único operador de produção de sentido dos mesmos $^{7}$. Em outros processos de leitura mais temática dos filmes africanos, é a dicotomia "tradição $x$ modernidade" que é construída como operador de análise e modo de produção de sentido no ato interpretativo.

São essas lógicas de leitura e interpretação sedimentadas e reatualizadas que formam a base daquilo que podemos chamar de cumplicidade não-programada entre o campo das pesquisas acadêmicas e o campo das propostas poéticas dos cineastas africanos. Essa problemática hermenêutica está presente também na análise que Dudley Andrew (1995) dedica ao filme Yeelen. Mais precisamente, foi a ambiguidade que cercou a recepção e as leituras desse primeiro filme africano premiado em Cannes, objeto da própria leitura de Dudley (1995). Yeelen foi aclamado pelo mundo ocidental, diz Andrew (1995), mas o filme não deixou de levantar perguntas quanto à sua proposta temática e estética. Não há dúvida que, de um lado, o filme de Cissé servia ao tema da magia e do misticismo africanos numa bandeja de prata para "os gostos de cinéfilos ocidentais". Mas, por outro lado, pergunta o teórico americano, ao fazer essa opção, será que o diretor de Yeelen não acabou abdicando do "papel formador e revolucionário que uma situação pós-colonial exigia de qualquer artista que possui uma consciência social?".

7 É incontável o número de teses e de livros com propostas de leitura pós-colonial dos filmes africanos, inclusive os mais contemporâneos. Porém o professor e estudioso americano da Michigan State University, Ken Harrow, numa recente publicação, questiona o uso indiscriminado da grade de leitura "pós-colonial" para ler os cinemas africanos. O título do seu livro é significativo dessa ruptura com velhos operadores de leitura dos cinemas africanos contemporâneos: "Trash: African cinema from below" (2013). Ou seja, inicia-se uma tendência em explorar novos horizontes e abarcar, no campo discursivo acadêmico, os filmes africanos populares, além da tradicional safra de filmes de autor. 
Como podemos ver, é, de novo, a questão da continuidade ou da descontinuidade entre horizontes de expectativa que está em jogo nessa recepção de Yeelen no espaço "ocidental". "Os africanos familiarizados com esse conto (ou o gênero ao qual ele pertence) e os espectadores ignorantes (principalmente os europeus e os admiradores do cinema americano) passam, com certeza, por experiências diferentes, mesmo se é verdade que todos são tocados pela aventura iniciática do herói do filme (ANDREW, 1995, p. 121). Mesmo assim, a diferença entre os espectadores ocidentais, sobretudo os estudiosos e teóricos do cinema, e os públicos africanos está no fato de que os primeiros procuram em Yeelen aquilo que os segundos já veem como uma recriação: "a maioria dos intelectuais e cineastas ocidentais não se volta para a África para encontrar uma fonte de espiritualidade que não podem encontrar nas suas culturas?" (Andrew, 1995, p. 111). Na leitura que Andrew faz do filme Yeelen, cruzam-se questões atinentes tanto ao programa narrativo, à escolha temática, ao discurso e à estratégia enunciativa do filme, como aos modos de leituras e interpretação que acompanham sua recepção no espaço ocidental e acadêmico, em particular. O próprio hermetismo do filme o destina a uma série de análises que querem descobrir seus sentidos "escondidos". A natureza "excepcional" de Yeelen, diz Dudley, deve-se em grande parte à forma como põe em cena a magia e o sagrado, e também ao tipo de temporalidade que instaura na ordem narrativa e do lado da instância da recepção. Como Yeelen, outros filmes autorais vinham, desde aqueles anos de consagração dos cinemas africanos na academia e nos festivais, apostando em estratégias narrativas e temáticas que se afirmavam como os únicos caminhos possíveis para o reconhecimento, razão pela qual Dudley cita outro autor-teórico e grande conhecedor dos cinemas africanos, André Gardies:

Fad'jal, Touki-Bouki, Contrast-City, ou Yeelen, em particular, estariam traçando um caminho diferente? Ao deslocar os códigos narrativos dominantes, ao reproduzirem um verdadeiro trabalho de escritura, ao brincarem com o poder da ambivalência, não só eles se desmarcam do desejo didático das leituras monossêmicas, mas ainda eles fazem ouvir uma voz singular e autêntica. (GARDIES, 1989, p. 175).

Desde então, os modos de leitura dos filmes africanos no espaço acadêmico vêm oscilando entre essa busca pelo novo e pelo diferente. Os diferentes actantes do espaço de recepção acadêmica parecem formados por pequenas comunidades de interpretação em que circulam os mesmos operadores de produção de sentido. As preocupações analíticas e temáticas desenvolvidas por Dudley (1995) em "New discourses of African cinema" encontram-se em outro texto de sua autoria numa outra importante revista universitária de cinema, CinémaAction no. 106, 2003. O dossiê Cinémas africains, une oasis dans le désert é uma ampla releitura do estado da arte das cinematográficas negro-africanas ${ }^{8}$ que vários pesquisadores universitários propõem em seus respectivos artigos. É neste espaço que Dudley (2003) opta por um modo de leitura deleuziano. Em seu artigo intitulado "Enraciné et en movement : les

\footnotetext{
${ }^{8}$ Um ano depois desse número sobre os cinemas da África negra, a revista CinémAction dedicava um dossiê exclusivo aos cinemas do norte da África: "Cinémas Du Maghreb", sob a direção de Michel Serceau ( $\left.n^{\circ} 111,2004\right)$. Na verdade, trata-se de um número que faz o balanço sobre o cinema magrebino, 20 anos depois de a revista ter lhe consagrado um primeiro número especial.
} 
contradictions du cinéma africain", ele usa os conceitos de nomadismo, de errância e de movimento (como operadores analíticos) para descrever e problematizar "as contradições do cinema africano" presentes em alguns filmes africanos contemporâneos $^{9}$. Dudley começa seu texto com a seguinte observação: "o único cineasta africano que Deleuze mencionou é, na verdade, aquele que sempre foi considerado como um narrador de contos, um cineasta-griot: Ousmane Sembène ${ }^{10 "}$ (2003, p.17).

A contradição do movimento e do enraizamento que Andrew Dudley identifica na filmografia de alguns cineastas como Sembène Ousmane não concerne apenas ao seu modo de construção narrativa e temática dos seus filmes (recorrência do tema do nomadismo, de um lado, e a fixação nos valores de uma África pré-colonial e o desejo de reapropriação do espaço africano na narrativa, por outro). Tal contradição se refere também ao modo de circulação dos próprios cineastas nos diferentes espaços de recepção pelo mundo (sobretudo, nos festivais). Para Andrew, há certa semelhança entre as figuras do personagem-nômade (que abundam nos filmes pós-coloniais africanos) e o movimento dos sujeitos cineastas. Os próprios cineastas africanos parecem destinados e condenados a viver como "migrantes que se deslocam de festival a festival, de universidade a universidade, para apresentar suas obras" (Andrew, 2003, p.22). O espaço onde se desenrola esta existência errática dos cineastas africanos é prioritariamente o espaço "ocidental", onde também suas obras encontram suas comunidades de intérpretes divididas entre cinéfilos, críticos e pesquisadores acadêmicos.

\section{Os cinemas africanos e o espaço discursivo "ocidental"}

À primeira vista, a experiência de leitura configurada por uma revista acadêmica (no nosso caso, uma revista que consagra um dossiê aos cinemas africanos) parece remeter, por alguns de seus aspectos, à questão do campo de referência e ao espaço discursivo que Odin (2011) denomina o "espaço ocidental". A prática de análise que tal dossiê desencadeia põe em cena as ações interpretativas de atores sociais e de comunicação, que são, na maioria das vezes, professores universitários e pesquisadores ou críticos. São, portanto, espectadores teóricos que pertencem ao mundo "ocidental" e que mantêm uma relação de alteridade com textos fílmicos oriundos de outros contextos culturais não-ocidentais. Porém, como lembra bem Odin (2011), seria errado e limitador atrelar a realidade do "ocidente" apenas a questões de ordem geográfica, política e ideológica. Ao definir as bases epistemológicas e culturais em que se sustenta o paradigma semiopragmático, Odin (2011) faz a seguinte observação, que, a nosso ver, funciona como um complemento de definição dos fatores contextuais que incidem na recepção, na leitura e nas interpretações dos filmes africanos em determinados contexto sócio-culturais não africanos:

\footnotetext{
${ }^{9} \mathrm{O}$ título do artigo é "Enraciné et en mouvement : les contradictions du cinéma africain".

10 Tal referência de Deleuze a Sembène foi efetivamente feita no oitavo capítulo do seu famoso livro "L'image-temps". Deleuze define o cinema de Sembène e do terceiro mundo como uma máquina de fabulação que oscila entre assunto privado e política; como um "cinema de ato de fala" que escapa da ficção e da etnologia. Isso garante, diz Deleuze, a liberdade e a circulação da fala do cinema africano e confere particularmente um valor de "enunciado coletivo" aos filmes de Sembène. (DELEUZE, 2007, p.265).
} 
Proponho considerar que o espaço discursivo construído neste livro tem a ver com o espaço ocidental. (...) Mais precisamente, o adjetivo "ocidental" visa a dar conta do fato de que esses processos são construídos a partir da minha experiência de ator da comunicação e de meu sentimento de que esta experiência é compartilhada com um vasto conjunto de (outros) atores. (ODIN, 2011, p. 45).

Ou seja, se existe um espaço discursivo "ocidental" nas revistas acadêmicas onde os cinemas africanos estão em análise, esse espaço não passa de uma "ficção teórica" tanto quanto o "ocidente". (ODIN, 2011, p. 45). Com outras palavras, E. Said (2003) faz a mesma ressalva ao dizer que a linha que separa o Oriente do Ocidente é mais um fato da produção humana do que da natureza. Por ser uma divisão fictícia, Said (2003) prefere falar de "geografia imaginativa" (p. 62). É nela que um conjunto de atores, ligados por um mesmo sentimento de pertencimento a uma comunidade de pesquisadores teóricos (africanistas ou não), produz uma reflexão teórica densa sobre os cinemas africanos, geralmente, em inglês ou em francês. A estrutura bilíngue do dossiê da Revista IRIS, por exemplo, é significativa. O bilinguismo começa pelo título do dossiê. Em seguida, os artigos em inglês e em francês são intercalados. Seus respectivos resumos são feitos nas duas línguas. A maioria dos autores que participaram desse número é docente nas universidades americanas, francesas e canadenses. É bom lembrar também que a Revista IRIS é uma revista de cinema de referência publicada pelo Institute for Cinema and Culture da Universidade de Iowa (EUA).

Ou seja, mesmo sendo geográfica e historicamente localizados na Europa e na América, os centros de estudos africanos, as unidades de estudos das literaturas e cinemas africanos contam também com a participação de pesquisadores e professores africanos. Ao seu modo, estes últimos fazem parte do espaço discursivo "ocidental". A comunidade de intérpretes dos cinemas africanos no espaço acadêmico é, portanto, mais heterogênea do que podemos imaginar. Se examinarmos, portanto, a formação dos discursos sobre os cinemas da África pelas perspectivas geopolítica, histórica e genealógica, reencontraremos alguns paradoxos e contradições presentes nos discursos críticos e teóricos "ocidentais"11 construídos sobre as realidades culturais e artísticas do "Outro". Em reação a esse "ocidentalocentrismo" dominante, surgiram três correntes intelectuais conhecidas como Critical race studies, estudos pós-coloniais e subaltern studies. Para Achille Mbembe (2000), essas áreas de estudo provocaram uma "revolução" nos diversos contextos de construção de saberes, não só por terem criado seus próprios objetos de estudos, seus léxicos e seu arsenal teórico, mas, sobretudo, por terem marcado uma espécie de "irrupção" dos intelectuais das excolônias nos campos dos debates sobre questões como diásporas, raça, diferença sexuada, alteridade, formas culturais e artísticas, ${ }^{12}$ etc. (MBEMBE, 2000, p. III). A

11 Usamos aqui "ocidente" e "ocidental" com toda a cautela possível e pensando em todas as complexidades e conotações diversas dessas palavras. Tentamos evitar assim os efeitos de sentido maniqueístas ligados ao uso reiterado desses termos no campo da produção do conhecimento e, por outro lado, procuramos escapar da cegueira dogmática à qual levou uma crença total no antagonismo "ocidental" X "não ocidental".

12 Enquanto nos países anglo-saxões essa "irrupção" do Outro no debate teórico foi bem recebida, na França, por exemplo, houve certa resistência em aceitar as teses e os conceitos dos Subaltern studies, Critical race studies ou dos estudos pós-coloniais por causa da onipresença das tradicionais áreas de conhecimento que são as ciências sociais e humanas, a teoria literária 
participação desses intelectuais de áreas culturas "periféricas" se deveu também à disposição do sistema universitário americano que, ao receber uma nova geração de intelectuais e de pensadores nos seus institutos, promoveu a centralidade de suas ideias e seus conceitos sobre algumas dessas questões. É nesse contexto que o próprio Mbembe situa os seus trabalhos e seus livros naquilo que chama de "arquivo dos discursos sobre a África" (2000, p. I).

Quanto à contribuição dos estudiosos do cinema que são de origem africana, ela interveio de forma tardia, mas foi decisiva na redefinição teórica dos cinemas africanos, seguindo e aproveitando algumas brechas abertas pelos estudos culturais. Foi também uma forma de participação na constituição desse infinito arquivo do discurso moderno sobre a África, de que fala Mbembe (2000). Na história das literaturas negro-africanas, por exemplo, o movimento da "negritude" já havia dado o tom. Em Discours sur le colonialisme (2004), Aimé Césaire dá uma definição da "negritude" que resume o voluntarismo com que os primeiros intelectuais, os escritores e poetas (e mais tarde os cineastas) queriam renovar a reflexão sobre as realidades sócio-culturais e artísticas de origem negro-africana: "a Negritude resulta de uma atitude ativa e ofensiva do espírito", diz Césaire (2004). A atitude paternalista do Ocidente para com a cultura do colonizado passa a ser o objeto de crítica do discurso da subalternidade; questiona-se a maneira como são aplicados valores falsamente universais à cultura do outro. Sendo assim, a revolta da "negritude" não podia desembocar num impasse, diz Césaire (2004). Ao contrário, ela levou o subalterno ou o colonizado para si, isto é, ajudou-o a assumir seu passado, "através da poesia, do imaginário, do romance das obras de arte, da fulguração intermitente" de seu possível devir (CÉSAIRE, 2004, p. 85). E para aqueles que se contentam a reduzir a "negritude" a um mero movimento literário ou a uma "especulação intelectual", Césaire (2004) adverte: "Mas nem a literatura, nem a especulação intelectual são inocentes ou inofensivas" (p. 86). A "negritude" foi uma das primeiras formas de participação real dos intelectuais e escritores da África e das diásporas negras africanos no processo de formação de um pensamento teórico estruturado sobre as realidades das culturas negro-africanas. A própria polêmica entre os defensores da "negritude" e da tigritude ${ }^{13}$ é a prova da necessidade que os primeiros intelectuais sentiram em instaurar um debate de ideia e de conceitos em torno da sua atividade poética e literária. Nessa efervescência teórica surgiram conceitos e modelos de pensamento estruturante para explicar e definir a literatura e a cultura negroafricana. O legado teórico da "negritude", dos estudos culturais e da subalternidade tem servido até hoje de referência nas reflexões de muitos teóricos, historiadores, artistas e cineastas africanos contemporâneos.

etc. Jean-François Bayart resume bem essa situação em seu livro Les études postcoloniales: un carnaval académique, 2010. Ver também um balanço sobre a recepção e situação dos estudos culturais na França e no mundo francófono em La situation postcoloniale, de Marie-Claude Smouts (Org.), 2007 (com prefácio de Georges Balandier).

${ }^{13}$ Foi atribuída ao escritor nigeriano Wole Soyinka uma das frases mais famosas e polêmicas nos estudos literários africanos: "O tigre não proclama sua tigritude. Ele agarra sua presa e a devora". 


\section{Conclusão}

As contradições que pontuam as leituras acadêmicas dos filmes africanos fazem parte do seu modo de recepção transnacional. Parte das interpretações é predeterminada pelas "ideologias" que configuram as próprias instituições universitárias $^{14}$. Paradoxalmente, a voz dos teóricos e dos cineastas africanos ecoa menos nessa logorreia. A negociação do sentido de filmes continua protagonizada pelos únicos teóricos e críticos ocidentais do cinema. Ora, há muito tempo que os cineastas africanos provaram que eram capazes de construir narrativas e discursos que comportassem uma parcela da "magia e do sagrado" (como a crítica ocidental esperava deles) e que seus filmes podiam ser portadores de uma forma de "pensamento" e de concepção estética particular do cinema. A participação dos próprios teóricos, críticos e cineastas africanos naquilo que podemos chamar de nova "partilha do sensível ${ }^{15 "}$ sobre os filmes africanos continua uma questão espinhosa. Ela atravessa em filigranas e com palavras veladas a proposta de algumas coletâneas. 0 postulado de um pensamento cinematográfico proveniente das margens revela visões diferentes com respeito a um mesmo objeto de estudo, mas, por outro lado, ele confirma, na perspectiva semiopragmática, a existência de actantes envolvidos em processos de leituras estéticas, formalistas e temáticas do mesmo objeto fílmico, mas com valores ideológicos divergentes. Numa análise semiopragmática dessa luta no espaço universitário, os diferentes protagonistas (historiadores, críticos e os cineastas) podem ser lidos como enunciadores reais que ocupam níveis de enunciação diferentes nesse processo de leitura e análise teórica dos cinemas africanos. É no contexto desse campo teórico e discursivo (entendido aqui como "espaço universitário" de recepção) que os dossiês de algumas revistas de cinema ganham todo o seu sentido. É um campo que revela lógicas, horizontes de expectativas e também actantes teóricos e pesquisadores, às vezes disputando a legitimidade de falar dos filmes africanos.

Com vimos, Roger Odin (2011) inaugura não só um modelo de análise fílmica, mas também abre uma nova perspectiva de estudo do fenômeno da recepção em que se levam em conta tanto os fatores contextuais quanto os textuais. Os modos de leitura, mesmo sendo programados e solicitados durante o processo de produção fílmica, precisam ser atualizados concretamente pelos espectadores nos espaços de recepção. Embora o termo de "espaço de comunicação" possa se prestar à confusão, ainda mais por se tratar de experiências estéticas cinematográficas, ela não deixa de ser de grande valia para a análise pormenorizada tanto dos processos de leitura fílmica como das práticas discursivas que toma, às vezes, a recepção cinematográfica. Por outro lado, a noção de "espaço de comunicação" parece em adequação com a lógica da abordagem semiopragmática mais interessada em entender e descrever aquilo que Bettetini (1996) chama de "projeto pragmático" dos filmes. Essa dimensão pragmática

14 Incluímos aqui o universo editorial, as traduções de obras teóricas, os congressos, as conferências, etc, e que forma o circuito daquilo que Bourdieu chama de "circulação internacional das ideias" (1990)

${ }^{15} \mathrm{~A}$ partilha do sensível, diz Rancière (2005), é "um sistema de evidências sensíveis que revela, ao mesmo tempo, a existência de um comum e de recortes que, nele, definem lugares e partes respectivas" (p.15). 
inerente a qualquer discurso fílmico o predestina a uma espécie de "conversação" com o espectador. Ou seja, todo filme é portador de seus próprios operadores de leitura/interpretação, enquanto outra parte do processo de interpretação depende de diversos fatores e determinações contextuais e institucionais.

\section{Referências}

ANDREW, DUDLEY. "Falaises sacrées et espaces communs". In IRIS (Revue de théorie de I'image et du son/A journal of theory on image and sound), v. 18, 1995, p. 113123

Enraciné et en movement: les contradictions du cinema africain.

CinémAction (dossiê Cinémas africains, une oasis dans le desert), v. 106, 2003, p. 16-24.

BARLET, Olivier. Les cinémas d'Afrique noire: le regard en question. Paris :

L'Harmattan, 1996.

BAYART, Jean-François. Les études postcoloniales: un carnaval académique. Paris: Karthala, 2010.

BETTETINI, Gianfranco. La conversación audiovisual: problemas de la enunciación fílmica y televisiva. Madrid: Catedra: Signo y Imagen, 1996.

BOURDIEU, P. "Les conditions sociales de la circulation internationale des idées".

RZLG, v. 14, 1990, p. 5-6

CÉSAIRE, Aimé. Discours sur le colonialisme. Suivi de discours sur la négritude. Paris: Présence Africane. 2004.

CRETON, Laurent; MOINE, Raphaëlle (Orgs.). Le cinéma en situation: expériences et usages du film. Paris: Presses Sorbonne Nouvelle, 2012.

DELEUZE, Gilles. A imagem-tempo. Cinema II. São Paulo: Ed. Brasiliense, 2007, p. 264-265

DIAWARA, Manthia. (Org.). Black American cinema. New York: Routledge, 1993.

ELSAESSER, Thomas; HAGENER, Malte. Film theory: an introduction through the senses. New York/London: Routledge, 2010.

ETHIS, Emmanuel. Les spectateurs du temps: pour une sociologie de la réception du cinéma. Paris: Ed. L'Harmattan/Sociologie des Arts, 2006.

EZRA, E.; ROWDEN, T. (org.). Transnational cinema: the filme reader. New York: Routlege, 2006

FRODON, Jean-Michel. La projection nationale: cinéma et atnion. Paris: Odile Jacob, 1998.

(Org.). Au Sud du cinéma: films d'Afrique, d'Asie et d'Amérique Latine. Paris: Cahiers du Cinéma/ARTE Étidions, 2004. 
GARDIES, André. Cinema d'Afrique noire francophone: L'espace miroir. Paris: L'Harmattan. 1989.

HARROW, Kenneth. Postcolonial African cinema: from political engagement to postmodernism . Bloomington: Indiana University Press, 2007.

Trash: African cinema from Below. Bloomington/Indianapolis: Indiana University Press, 2013.

HAYWARD, Susan. French national cinema. Londres: Routledge, 2005 (2a edição). HIGSON, Andrew. "The concept of national cinema". Screen, v. 30, n. 4, 1989, p. 36

LACASSE, Germain. Le bonimenteur et vues animées: le cinéma "muet" entre tradition et modernité. Québec/Paris: Nota Bene/Méridiens Klincksieck, 2000.

MASILELA, Ntongela. The Los Angeles School of Black filmmakers. In: DIAWARA, Manthia (Org.). Black American cinema. New York: Routledge, 1993, p. 107-117 MBEMBE, Achille. De la postcolonie: essai sur I'imagination politique dans I'Afrique contemporaine. Paris: Karthala, 2000.

Sortir de la Grande Nuit: essai sur I'Afrique décolonisée. Paris: La Découverte, 2010.

NAFICY, Hamid. An accented cinema: exilic and diasporic filmmaking. New Jersey: Princeton University Press, 2001.

. Situating accented cinema. In: EZRA, E. (Org.). Transnational cinema: the film reader. New York: Routlege, 2006, p. 111-129.

ODIN, Roger. De la fiction. Bruxelles: De Boeck \& Larcier, 2000.

. Le film de famille dans I'instituition familiale. Roger Odin. Le film de famille: usage privé, usage public. Liège: Méridiens Klincksieck, 1995. p.29-41 La question du public, appproche sémio-pragmatique. In: Les espaces de communication: introduction à la sémio-pragmatique. Grenoble: PUG, 2011.

RANCIÈRE, Jacques. A partilha do sensível: estética e política. São Paulo: EXO Experimental/Ed. 34, 2005.

SAID, Edward. Reflexões sobre o exílio: e outros ensaios. São Paulo: Companhia das Letras, 2003.

SERCEAU, Michel. Le cinéma d'Afrique noir francophone face au modèle occidental: la rançon du refus. In IRIS: Revue de théorie de I'image et du son/A journal of theory on image and sound, v. 18, 1995, p. 39-46

20 ans déjà!. CinémAction (dossiê Cinémas du Maghreb), v. 111, 2004, p.

7-9.

SMOUTS, Marie-Claude (Org.). La situation postcoloniale. Paris: Sciences PO, 2007. 
STAIGER, Janet. Perverse spectators: the practices of film reception. New York: New York University Press, 2000.

STAM, Robert. Introdução à teoria do cinema. Campinas: Papirus, 2003. p. 112121

STAM, Robert; SHOHAT, Ella. Teoria do cinema e espectatorialidade na era dos "pós". in RAMOS, Fernão (org.). Teoria contemporânea do cinema: pós-estruturalismo e filosofia analítica, V. I. São Paulo: SENAC, 2005. p. 393-424

Multiculturalismo tropical: uma história comparativa da raça na cultura e no cinema brasileiro. São Paulo: Edusp, 2007.

TSIVIAN, Yuri, Early cinema in Russia: and its cultural reception. Chicago/Londres: The University of Chicago Press, 1998.

Title: The reception spaces of transnational cinemas: proposals for a semiopragmatics approach

Abstract: What are the determinations contextual and institutional involved in reception transnational films? Following a line of thought that lies between geopolitical and semiopragmatics contemporary film approaches, we bring some theoretical and methodological considerations about modes of reading and interpretation of world cinema in academic spaces. We review the main theoretical conceptions about the phenomenon of "transnationality". Examine the logic of forming communities of interpretation, value systems and the horizons of expectations in the heteroclite entity defined by Elsaesser and Hagener (2010) as "transnational community of ideas." We start by this category (geographical, while theoretical) to rethink the studies of world cinema as a field of micro-communication spaces, reception and reading filmic (ODIN, 2011). By this theoretical reconstruction, we re-evaluate, finally, the issue of (in) variants in the negotiation process of the senses of contemporary films Africans in the "discursive space" university.

Keywords: Transnational Cinema. Reception. Africain cinema. Semiopragmatics.

Recebido em: 06/09/2013. Aceito em 30/11/2013. 